\title{
Time to align: development cooperation for the prevention and control of non-communicable diseases
}

\author{
Téa Collins and colleagues call for coordinated global action to catalyse effective national \\ responses to non-communicable diseases
}

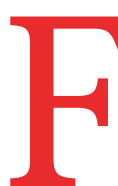

inancing sustainable development, especially for health, is important for dealing with the tremendous challenges faced by low income countries. Many cannot meet their populations' basic needs from domestic public resources alone. Traditionally, high income countries have considered external assistance to be a foreign policy matter, influenced by national political and economic considerations. They have usually seen areas of health, such as infectious diseases, as having major implications for their national security.

Until recently, however, noncommunicable diseases (NCDs) have not been seen as part of the global development agenda, and external resources for their prevention and control have been negligible. A change in the disease profile from communicable diseases to NCDs in low and middle income countries resulted in the inclusion of NCDs in the 2030 agenda for sustainable development. Nonetheless, health systems in those countries are ill prepared to deal with the

\section{KEY MESSAGES}

- Investments in NCD prevention and control offer great potential to countries at all income levels to advance their economic growth

- Adequate catalytic development funds for NCD prevention and control are particularly important in low income and fragile countries, where resources are limited but the needs are great

- Traditional North-South development assistance is increasingly being replaced by South-South and triangular cooperation

- Scope and funding of national multisectoral plans for NCD prevention and control are insufficient, perpetuating a misalignment between development cooperation and the needs and priorities of recipient countries high epidemiological and economic costs of chronic conditions. These conditions have now been recognised in global political forums.

The increasing importance of NCDs in the development agenda was validated by the three United Nations General Assembly high level meetings on non-communicable disease prevention and control (in 2011, 2014, and 2018) and the 2030 agenda for sustainable development. The agenda includes a target of one third reduction of premature mortality from NCDs by $2030 .^{2}$

The 2030 agenda also emphasises the importance of official development assistance. It calls on high income countries "to reaffirm their commitment to achieve the target of $0.7 \%$ of gross national income for official development assistance to developing countries." 3

What does the combination of greater political intent and weak existing ability to deal with NCDs mean for development assistance for health? A clear answer to this question is particularly important for low income and fragile countries, where government spending on health is low, public institutions and regulatory bodies are weak, and reliance on external help for basic health needs is high. We examine the challenges of mobilising and tracking resources for NCDs. Additionally, we highlight the importance of international cooperation to accelerate progress towards the NCD and the related targets of the 2030 agenda.

\section{Moving to the sustainable development goals (SDGs): the need to prioritise NCDs}

The millennium development goals era witnessed a major transformation of global health architecture. This was truly a period of "innovation and experimentation," in channelling development assistance for health. Vertical control programmes to deal with HIV/AIDS, tuberculosis, and malaria were set up, and new and underused vaccines introduced. ${ }^{4}$ During 2000-10, development assistance for health grew from \$12bn (€9.5bn, €10.6bn) to almost $\$ 34 \mathrm{bn} .^{5}$ At its peak in 2013, financial assistance in countries with limited resources reached $\$ 38 \mathrm{bn}$, with an annual growth rate of $9.7 \%$ between 2000 and $2013 .{ }^{6}$

However, NCDs were excluded from the millennium development goals and the donor response was poor. Even though the proportion of deaths from NCDs has risen, assistance for NCDs has remained mostly unchanged. In 2018, less than $2 \%$ of the total development assistance for health (\$778.3m) was allocated to NCDs.

Major NCDs (cardiovascular diseases, cancer, chronic respiratory diseases, and diabetes) continue to be neglected by donors, although they have long been the leading cause of death globally, except for sub-Saharan Africa. In 2016, 41 million of 56 million deaths worldwide were due to NCDs. More than three quarters (78\%) of NCD mortality was in low and middle income countries; $47 \%$ of these deaths were premature, affecting people aged 30-70 years. ${ }^{2}$ These levels are growing steadily.

The economic cost of NCDs, including mental health, was estimated to be $\$ 47 \mathrm{tn}$ for lower and middle income countries between 2011 and 2030. ${ }^{8}$ Investments in NCD prevention and control offer opportunities to all countries to advance their economic growth. Every dollar invested now is expected to yield a return of at least 7 dollars by $2030 .^{9}$ The Lancet taskforce on NCDs and economics demonstrated that progress towards SDG 3.4 will positively influence at least nine other SDGs-namely, SDG 1 (reducing poverty), SDG 2 (zero hunger), SDG 3 (health and wellbeing), SDG 4 (education), SDG 5 (gender equality), SDG 8 (decent work and economic growth), SDG 10 (reduced inequalities), SDG 11 (sustainable cities and communities), and SDG 12 (sustainable production and consumption). ${ }^{10}$

We emphasise that for most countries development assistance for health is 
not, and will not be, a substantial source of health funding. Even in countries with limited resources, domestic public resources are the major source of health funding. Donor financing should be seen only as a temporary measure to meet basic health needs. The World Health Organization estimates the following as major funding sources for NCDs, in descending order: government revenues ( $92 \%$ of countries rely on this source); health insurance (62\% of countries); international donors (62\%); national donors (44\%); earmarked taxes (39\%); and others $(26 \%) .{ }^{11}$ However, development assistance for health is essential for averting preventable deaths from NCDs in countries with insufficient resources. Recent estimates show that low and lower middle income countries will need to spend $\$ 97$ per capita on a high priority package of health services. ${ }^{12}$ No low income country can yet provide that level of health services. At least 25 countries will continue to need external assistance for health by $2026 .^{13}$

\section{Challenges in rectifying the funding deficit}

Definition of NCDs-Increasing development assistance for NCDs is partly challenged by a problem of language. This is not the case for more defined areas of health, such as HIV/AIDS or maternal and child health. The risk factors and presentations of NCDs are so disparate that tracking the flow of resources into NCD prevention and control is imprecise. For example, urban planning projects that encourage walking or green spaces may be labelled as emission reduction programmes, without recognising that higher levels of physical activity improve NCD outcomes. The definition of NCDs has also been broadened with the move away from the " $4 \times 4$ approach" (four major NCDs and four modifiable risk factors) to the " $5 \times 5$ approach", which includes mental health and environmental determinants (principally, air pollution).

Perception of NCDs-NCDs are still not widely considered part of broader development for altering environments for human flourishing. The immediate risk factors for NCDs (tobacco and alcohol use, poor diets, and lack of exercise) are predominantly considered to be due to personal decisions. At the same time, metabolic risk factors, including high blood pressure, obesity, hyperglycaemia, and hyperlipidaemia, require interventions by healthcare providers. ${ }^{14}$ Therefore, action on NCDs too often remains confined to health systems, with inadequate attention paid to the underlying social determinants of NCDs outside the health sector and beyond an individual's control. ${ }^{15}$

Major donor countries not meeting their commitments-Of the 23 major donor countries, 17-including the United States, Canada, France, Germany, and Japan-do not meet internationally agreed targets for development assistance for health. If these 17 countries had kept their commitments, an additional $\$ 13.3 \mathrm{bn}$ would have been available for global health in $2016 .{ }^{5}$ In addition, because an increasing share of assistance for health is channelled through multilateral agencies and non-governmental organisations, the resources are used in areas of interest to these institutions (not necessarily for NCDs). Thus, the effectiveness of aid for harmonisation, alignment, and country ownership remains unattained.

Allocation of assistance to countries is misaligned with need-The mismatch between the burden of disease and allocation of assistance for NCDs is increased further by an imbalance in resources allocated to countries. The countries with the highest NCD burden are not necessarily those that receive the assistance allocated to these needs. ${ }^{5}$

Newer donors-Donors that do not report to the $O E C D$ Development Assistance Committee, such as, China, India, Iran, Kazakhstan, Kuwait, Russia, and South Africa, contribute significant resources, but their contributions remain poorly documented. For example, it is estimated that the new sources of funding represent up to two thirds of total official development assistance to Tajikistan. ${ }^{16}$

Graduation of countries from health aid-As national economies grow, and low income countries achieve middle income status, donors are introducing "graduation rules.” External assistance is discontinued at a certain level of gross domestic product. Countries are then expected to fund their own healthcare. Unfortunately, many of these new middle income countries have persistent inequalities of health and income. The growing burden of NCDs cannot be dealt with without external assistance.

Low assistance for health system strengthening-To attain the health related sustainable development goals, including the NCD target (SDG 3.4) and the NCD related targets of the 2030 agenda, a higher proportion of development assistance for health should be invested in countries' efforts to achieve universal health coverage. Donor investments in health systems continue to be low, however, and the proportion of these funds assigned to NCDs is even lower. In 2015, $\$ 15.9 \mathrm{bn}$ (69.6\% of development assistance for health) was devoted to infectious diseases; reproductive, maternal, newborn, child and adolescent health; and NCD programmes (programme specific funding). The largest proportion was allocated to infectious diseases (fig 1) and only $1.8 \%$ to NCDs. ${ }^{17}$

Box 1 summarises the additional challenges to mobilising development funding of NCDs.

\section{Development cooperation for NCD prevention and control}

The fourth high level forum on aid effectiveness in Busan, Korea, 2011, moved the aid effectiveness model to development effectiveness. The Busan partnership agreement recognised the multistakeholder nature of the new international development cooperation beyond development assistance to incorporate other international collaboration flows. ${ }^{18}$ The 2030 agenda for sustainable development also includes a specific partnership goal (goal 17). North-South official development assistance is increasingly being replaced by South-South and triangular cooperation, which takes many different forms (table 1). This approach is well suited to international progression of a global NCD response. Boxes 2 and 3 give some examples.

\section{National multisectoral plans as a tool for development cooperation}

In countries where external assistance is important, national health policies, strategies, and plans are crucial to improving development effectiveness. To assess the ability of countries to respond to NCDs, WHO conducts periodic global surveys. Information is collected on countries' NCD infrastructure, policies for NCDs, surveillance, and health system response. Survey results over the years provide a valuable picture of global progress on NCDs.

\section{Infectious diseases $\mathbf{5 6 . 5 \%}$}

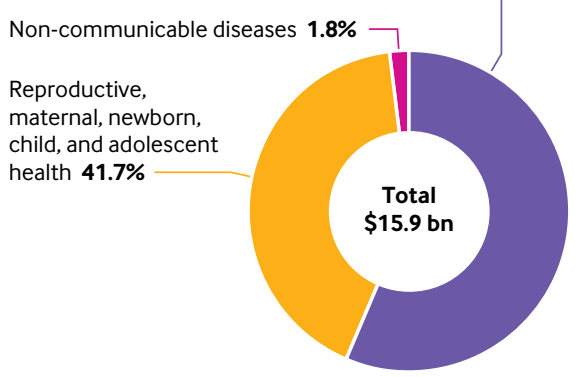

Fig 1 | Breakdown of programme specific investments across disease areas ${ }^{17}$ 
Box 1: Additional challenges to mobilising development assistance for health for NCDs

\section{Institutional inertia}

Institutional inertia impedes changes in spending patterns despite inclusion of NCDs in the 2030 agenda (SDG 3.4) and the Addis Ababa action agenda of the third international conference on financing for development. For low income countries that allocate $<5 \%$ of their gross national income to health, however, it is unrealistic to expect scaling up of national responses without the catalytic funding from donors.

Challenges due to allocations focusing on a particular area of health

Being part of SDG 3, NCDs now have to "compete" for scarce resources with many other global health priorities, including communicable diseases and reproductive, maternal, newborn, child, and adolescent health as well as the overall health system.

\section{Lack of governance structures at country level to present a coherent demand for NCD policy and planning}

Development requires a coordinated clarification of a country's priorities. National NCD plans may fail to account for the political nature of the development process, key stakeholder perspectives across government, the division of roles and responsibilities, and the necessary budget. This absence of, or inconsistencies in, national NCD plans and strategies may slow down global mobilisation of support.

\section{Change from bilateral and multilateral assistance to mixed forms of international cooperation}

Development cooperation is increasingly following a "mixed coalition" model, including both state and non-state actors and the UN agencies. This approach is more fluid than that of traditional global government institutions. It gathers together interested stakeholders, including nation states, as well as non-governmental organisations, private foundations, for-profit companies, and civil society organisations, for specific initiatives that may not necessarily be concerned with NCDs.

Lack of government ability to coordinate multiple donors and ensure coherence across sectors

Ministries of health in many low income countries are ill prepared to lead on the multisectoral NCD agenda and request additional resources through development assistance rather than mobilising assets across government institutions.

\section{Corporate interference dilutes global commitments and influences development assistance for NCDs}

Interference of the tobacco industry, which undermines country NCD prevention and control efforts, is well known. More research is needed to document the extent of corporate influence on international cooperation.

Slow recognition of NCDs as part of the development assistance for health reduces accountability of donors

The OECD development assistance committee creates the global framework for tracking donor assistance across sectors. Until 2019, there was no tracking of NCDs in that framework and therefore no systematic means of holding donors accountable for their commitments. There are now "purpose codes" for NCDs and several of their risk factors in the development assistance committee reporting system. Donor countries will use those codes to report financial flows for NCDs.

\begin{tabular}{|c|c|c|c|}
\hline \multirow{2}{*}{$\begin{array}{l}\text { South-South } \\
\text { Technical cooperation and } \\
\text { networking }\end{array}$} & \multicolumn{3}{|l|}{ Triangular } \\
\hline & Technical cooperation and training & Knowledge exchange programmes & Knowledge sharing networks \\
\hline $\begin{array}{l}\text { Governments and public institu- } \\
\text { tions }\end{array}$ & $\begin{array}{l}\text { Ministries and public institutions, in- } \\
\text { ternational agencies, NGOs, academic } \\
\text { institutions }\end{array}$ & $\begin{array}{l}\text { Multistakeholders, including research } \\
\text { institutions, ministries, NGOs, } \\
\text { international agencies }\end{array}$ & $\begin{array}{l}\text { Multistakeholders, including research } \\
\text { institutions, ministries, NGOs, } \\
\text { international agencies, foundations }\end{array}$ \\
\hline $\begin{array}{l}\text { Short term projects; sometimes } \\
\text { programmes with long term vision }\end{array}$ & $\begin{array}{l}\text { Long term vision but often translated } \\
\text { into short term projects }\end{array}$ & Short term projects & $\begin{array}{l}\text { Long term vision and long term } \\
\text { implementation }\end{array}$ \\
\hline Results are rarely monitored & $\begin{array}{l}\text { Results monitored, documented, and } \\
\text { shared }\end{array}$ & $\begin{array}{l}\text { Results monitored, documented, and } \\
\text { shared }\end{array}$ & Results rarely monitored \\
\hline
\end{tabular}

In $2017,88 \%$ of countries $(100 \%$ response rate from 194 WHO member states) reported having a national policy, strategy, or action plan that integrated several NCDs and their risk factors. Only
$71 \%$ of countries, however, indicated that their plan was operational. Fewer $(65 \%)$ had operational policies that were multisectoral, and only $51 \%$ had operational multisectoral policies that dealt

\section{Box 2: South-South cooperation: promoting healthy lifestyles ${ }^{4}$}

The Association of Southeast Asian Nations (ASEAN), which promotes healthy lifestyles, links priority areas for health promotion; key target groups based on stages throughout the lifespan; and key levels, sectors, settings, and strategies for implementation.

The Regional Action Plan on Healthy Lifestyles was introduced to strengthen ASEAN cooperation among member countries to promote healthy lifestyles, focusing on the following priority areas: accident and injury prevention; alcohol consumption; communicable disease control; healthy ageing; mental health; NCD prevention and control; nutrition; physical activity; substance misuse; tobacco control; and women's and children's health. with the four main risk factors and four main NCDs. ${ }^{9}$ Box 4 describes the challenges of developing national NCD plans that can be used to request external assistance.

\section{Conclusions}

Substantial external investments will be required to strengthen the ministries of health in low income countries, generate relevant NCD investment cases, ensure the development and full implementation of costed and financed national strategies, and establish multisectoral coordination mechanisms that ensure a full government response. However, external assistance should be seen as comple- 


\section{Box 3: Examples of triangular cooperation ${ }^{20}$}

\section{Universal health coverage}

Mexico, once a low spender on health, like the Philippines, has increased funding for its Seguro Popular programme more than 10 -fold in the past decade. The programme now covers over 40 million previously uninsured people. The World Bank connected health officials from the Philippines with Mexican peers to learn from their experiences in achieving sustainable universal healthcare. "The reforms in the health insurance system [in Mexico] started in 2003, while we are starting or about to start. Mexico provides a good example for the Philippines because in both countries universal healthcare is being implemented in a decentralised way," noted the secretary of health of the Philippines. ${ }^{20}$

This exchange of knowledge helped the Philippine participants understand best practices and challenges in organisational reform to achieve universal healthcare.

\section{Improving nutrition}

Senegal had extensive and successful experience with nutrition intervention, especially in decentralisation and community involvement. Senegal had also implemented several projects in the area funded by the World Bank. World Bank staff therefore connected Malawi with Senegal to learn about strategies for making nutrition more effective.

mentary and a catalyst for government and domestic financing, enabled by technical cooperation aligned with country priorities.

The Lancet Commission on Investing in Health argued that as countries' economies grow, donors should start investing in areas where national governments tend to underinvest. The authors suggested that donor financing should increasingly support international collective action for health or global functions that aim to deal with transnational challenges. For example, the commission emphasised that one of the important roles for such action is closing the gap between knowledge and action by supporting population, policy, and implementation research. ${ }^{4}$ This is particularly important for NCDs. Although cost effective interventions are available, evidence on how best to deliver them in different contexts and diverse populations is lacking.

For country specific assistance for NCDs, and to deal with imbalance in the allocations of development assistance for health to incorporate NCDs, we propose some immediate priorities.

Firstly, countries must be supported to have fully costed multisectoral action plans. The plans should incorporate actions by both government and civil society. They should also promote partnerships with the relevant private sector entities. However, the potential conflicts of interest should be effectively managed.

Secondly, countries need help to introduce robust intragovernmental coordination and oversight functions. The purpose is to optimise work across the whole of government and minimise incoherence

\section{Box 4: Alignment of NCDs in sector-wide health policies and plans: cases of five countries in the WHO Western Pacific Region}

After a qualitative analysis of five national plans-those of Cambodia, Fiji, Malaysia, Mongolia, and the Philippines-one study identified three major areas of concern about NCDs in low and middle income countries ${ }^{21}$

\section{NCD plans non-reflective of local needs and priorities}

The sector-wide health plans did not reflect local disease health needs. Often there was a conflict between local needs and global priorities; global priorities usually prevailed despite contradictory local evidence. The absence of NCD-specific units in the sector-wide health policy and planning process was apparent.

\section{Weak alignment between sector-wide and NCD-specific policies and plans}

The analysis also uncovered weak alignment between sector-wide and NCD-specific policies and targets and financial resource allocation. Division of roles and responsibilities between the NCD-specific and sector-wide structures was also unclear.

\section{Lack of financial analysis, costing, and feasibility to implement responses to NCDs} Of the five countries examined, only Fiji's NCD plan included costing and financing of the proposed interventions. The budget indicated, however, was a major underestimate. None of the plans (either sector-wide or NCD-specific) provided an analysis of the public health expenditure for NCDs, despite a substantial proportion of expenditure being spent on their treatment. between ministries and branches. Legislative bodies should be core to this.

Thirdly, full examination of legislative function and oversight for the regulation of products and processes harmful to health, including those of polluting industries, is vital for countries to be able to scale up their national responses.

Fourthly, international support will be required to help low and middle income countries to communicate the urgent need for accelerated investments in NCD prevention and control. The costs of inaction and the return of policy and expenditure built around WHO good and best buys for NCDs and the WHO Framework Convention on Tobacco Control must be calculated. A full review of the actual and potential benefits of health taxes on tobacco, sugar, and alcohol should be incorporated into these fiscal frameworks.

Finally, the integration of NCDs into universal health coverage assessment, planning, financing, and capacity building will need large scale normative and technical assistance.

For other articles in the series see www.bmj.com/ NCD-solutions

Contributors and sources:TEC conceptualised and wrote the manuscript and is the guarantor. RN and DW reviewed, commented on, and revised the manuscript. All other authors reviewed and commented on the manuscript. The views expressed in this article do not necessarily represent the views, decisions, or policies of the institutions with which they are affiliated.

Competing interests: We have read and understood BMJ policy on declaration of interests and have no relevant interests to declare.

Provenance and peer review: Commissioned; externally peer reviewed.

This article is part of a series proposed by the WHO Global Coordination Mechanism on NCDs and commissioned by The BMJ, which peer reviewed, edited, and made the decision to publish. Open access fees are funded by the Swiss Agency for Development and Cooperation, International Federation of Pharmaceutical Manufacturers and Associations (IFPMA), UNOPS Defeat-NCD Partnership, Government of the Russian Federation, and WHO. Téa E Collins, adviser ${ }^{1}$

Rachel Nugent, vice president ${ }^{2}$

Douglas Webb, team leader ${ }^{3}$

Erika Placella, deputy head ${ }^{4}$

Tim Evans, senior director

Ayodele Akinnawo, consultant ${ }^{1}$

${ }^{1}$ Global Coordination Mechanism on the Prevention and Control of Noncommunicable Diseases, World Health Organization, Geneva, Switzerland

${ }^{2}$ Global Noncommunicable Diseases, RTI International, North Carolina, USA

${ }^{3} \mathrm{HIV}$, Health and Development, UN Development Programme, New York, USA

${ }^{4}$ Global Programme Health, Swiss Agency for Development and Cooperation, Bern, Switzerland ${ }^{5}$ Health, Nutrition and Population Global Practice, World Bank, Washington, DC, USA 
Correspondence to: TE Collins collinst@who.int

\section{(c) $\underset{\mathrm{BY}}{(1)}$ (8) OPEN ACCESS}

This is an Open Access article distributed under the terms of the Creative Commons Attribution IGO License (https://creativecommons.org/licenses/ by-nc/3.0/igo/), which permits use, distribution, and reproduction for non-commercial purposes in any medium, provided the original work is properly cited.

\section{D) Check for updates}

1 Schieber GJ, Gottret P, Fleisher LK, Leive AA. Financing global health: mission unaccomplished. Health Aff (Millwood) 2007;26:921-34. doi:10.1377/ hlthaff.26.4.921

2 WHO. Global health estimates 2016: deaths by cause, age, sex, by country and by region, 20002016. World Health Organization, 2018. https:// www.who.int/healthinfo/global_burden_disease/en/

3 Transforming our world: the 2030 agenda for sustainable development. UN General Assembly, 2015, A/RES/70/1. https://sustainabledevelopment. un.org/post2015/transformingourworld

4 Jamison DT, Summers LH, Alleyne G, et al. Global health 2035: a world converging within a generation. Lancet 2013;382:1898-955. doi:10.1016/S01406736(13)62105-4

5 Nugent R. A chronology of global assistance funding for NCDs. Glob Heart 2016;11:371-4. doi:10.1016/j. gheart.2016.10.027

6 Micah AE, Zlavog B, Friedman S, et al. The US provided $\$ 13$ billion in development assistance for health in 2016, less per person than many peer nations. Health Aff (Millwood) 2017:36:2133-44. doi:10.1377/hlthaff.2017.1055

7 Institute for Health Metrics and Evaluation (IHME). Financing global health 2018: countries and programs in transition. IHME, 2019. http://www. healthdata.org/sites/default/files/files/policy_ report/FGH/2019/FGH_2018_full-report.pdf

8 Bloom DE, Cafiero ET, Jané-Llopis E, et al. The global economic burden of non-communicable diseases. World Economic Forum, 2011. http:// www3.weforum.org/docs/WEF_Harvard_HE GlobalEconomicBurdenNonCommunicable Diseases_2011.pdf

9 WHO. Saving lives, spending less: a strategic response to noncommunicable diseases. World Health Organization, 2018. https://www.who.int/ ncds/management/ncds-strategic-response/en/

10 Nugent R, Bertram MY, Jan S, et al. Investing in noncommunicable disease prevention and management to advance the sustainable development goals. Lancet 2018;391:2029-35. doi:10.1016/S01406736(18)30667-6

11 WHO. Assessing national capacity for the prevention and control of noncommunicable diseases: report of the 2017 global survey. World Health Organization, 2018. https://apps.who.int/iris/bitstream/hand le/10665/276609/9789241514781-eng.pdf

12 Watkins DA, Yamey G, Schäferhoff M, et al. Alma-Ata at 40 years: reflections from the Lancet Commission on Investing in Health. Lancet 2018;392:1434-60. doi:10.1016/S0140-6736(18)32389-4

13 Watkins DA, Yamey G, Schäferhoff M, et al. Alma-Ata at 40 years: reflections from the Lancet Commission on Investing in Health. Lancet 2018;392:1434-60. doi:10.1016/S0140-6736(18)32389-4

14 WHO. Global Health Observatory (GHO) data: risk factors. Geneva: World Health Organization. https:// www.who.int/gho/ncd/risk_factors/en/
15 UNDP and WHO Sectoral Briefs. What governments need to know about non-communicable diseases, 2019. https://www.undp.org/content/undp/en/home/ librarypage/hiv-aids/what-government-ministries-needto-know-about-non-communicable-diseases.html

16 WHO Regional Office for Europe. Review of coordination mechanisms, Tajikistan, summary report. WHO, 2009. http://www.euro.who.int/ data/assets/pdf file/0013/106411/E93771.pdf

17 Schäferhoff M, Yamey G, Kraus J, et al. Development assistance for health to achieve universal health coverage. Study commissioned by World Health Organization and UHC2030. WHO, 2017.

18 The Busan partnership for effective development cooperation. 2012https://www.oecd.org/dac/ effectiveness/Busan\%20partnership.pdf

$19 \mathrm{IHP}+/ \mathrm{UHC} 2030$. South-South and triangular cooperation in health. Current status and trends: summary of findings from an analysis undertaken on behalf of IHP+. World Health Organization and World Bank, 2014. https://www.uhc2030.org/fileadmin/ uploads/ihp/Documents/About_IHP_/what_we_do/ inp_south_south_and_triangular_cooperation_in health.pdf

20 Bollyky TJ, Templin T, Cohen M, Dieleman IL. Lowerincome countries that face the most rapid shift in noncommunicable disease burden are also the least prepared. Health Aff (Millwood) 2017;36:1866-75. doi:10.1377/hlthaff.2017.0708

21 Rani M, Nusrat S, Hawken LH. A qualitative study of governance of evolving response to noncommunicable diseases in low-and middle- income countries: current status, risks and options. BMC Public Health 2012;12:877. doi:10.1186/14712458-12-877

Cite this as: $B M / 2019 ; 366: 14499$

http://dx.doi.org/10.1136/bmj.l4499 